\title{
Evidence for Functional Release of Endogenous Opioids in the Locus Ceruleus during Stress Termination
}

\author{
Andre L. Curtis, Nicholas T. Bello, and Rita J. Valentino \\ The Children's Hospital of Philadelphia, 706 Abramson Pediatric Research Center, Philadelphia, Pennsylvania 19104
}

Endogenous opioids target noradrenergic locus ceruleus (LC) neurons and potently inhibit LC activity. Nonetheless, it has been difficult to demonstrate functional regulation of the LCnoradrenergic system by endogenous opioids because of the lack of effect of opiate antagonists. The present findings provide evidence that endogenous opioids regulate LC neuronal activity during the termination of a stressor. LC neuronal discharge was recorded from halothane-anesthetized rats before, during, and after hypotensive stress elicited by intravenous nitroprusside infusion. In naïve rats, mean arterial blood pressure was temporally correlated with LC activity such that hypotension was associated with increased LC discharge and a return to the normotensive state was associated with a decrease in LC discharge below pre-stress values. After microinfusion of an antagonist of the stress neuropeptide corticotropin-releasing factor (CRF) into the LC, the increase in
LC discharge associated with hypotension was prevented, whereas LC inhibition associated with termination of the challenge occurred at an earlier time and was of a greater magnitude. In contrast, microinfusion of naloxone into the LC completely abolished LC inhibition associated with termination of the stressor. Naloxone microinfusion did not prevent LC inhibition associated with hypertension produced by intravenous vasopressin administration, suggesting that endogenous opioids may be selectively engaged during the termination of hypotensive stress. These results provide evidence for a functional release of endogenous opioids within the LC. This action of endogenous opioids may serve to counterbalance excitatory effects of CRF on the LC-norepinephrine system, thereby limiting its activation by stress.

Key words: corticotropin-releasing hormone; opiate; locus ceruleus; norepinephrine; hypotension; naloxone
A role for endogenous opioids as brain neurotransmitters is supported by the distinct localization of opiate binding sites (Khachaturian et al., 1985; Mansour et al., 1988) and opioidcontaining neurons and axon terminals in brain (Uhl et al., 1979; Finley et al., 1981; Haber and Elde, 1982; Khachaturian et al., 1983; Fallon and Leslie, 1986), as well as the potent effects of opioid ligands within specific neural circuits (Williams et al., 1982; Wagner and Chavkin, 1995). Nonetheless, because it has been difficult to demonstrate effects of pure opiate antagonists in specific regions innervated by opioid-containing terminals, the precise function of opioid peptides has remained unknown. Potential functions of endogenous opioids have been best studied in the hippocampus (for review, see Wagner and Chavkin, 1995). Thus, high-frequency electrical stimulation of the perforant path altered IPSPs recorded in the CA3 region of the hippocampal slice in a naloxone-sensitive manner (Caudle et al., 1991). Antagonism by naloxone of long-term potentiation produced by high-frequency stimulation of the mossy fiber pathway (Derrick et al., 1992) or perforant pathway (Xie and Lewis, 1991) has implicated a role for endogenous opioids in long-term potentiation. It is noteworthy that high-frequency electrical stimulation was required to observe naloxone-sensitive effects in these studies.

Substantial evidence supports a neurotransmitter-neuromodu-

Received Jan. 23, 2001; revised April 2, 2001; accepted April 12, 2001.

This work was supported by Public Health Service Grants MH40008 and MH00840 (a Research Scientist Development Award to R.J.V.).

Correspondence should be addressed to Rita J. Valentino, The Children's Hospital of Philadelphia, 706 Abramson Pediatric Research Center, Civic Center Boulevard, Philadelphia, PA 19104. E-mail: valentino@email.chop.edu.

N. T. Bello's present address: Department of Neuroscience, Pennsylvania State University, Hershey, PA 17033.

Copyright (C) 2001 Society for Neuroscience $\quad 0270-6474 / 01 / 210001-\bullet \$ 15.00 / 0$ lator role for opioids in the noradrenergic nucleus locus ceruleus (LC). For example, the LC is innervated by enkephalin (Drolet et al., 1992), and LC dendrites are synaptically targeted by endogenous opioids (Van Bockstaele et al., 1995). Opiates and opioid peptides inhibit LC activity in vitro (Williams et al., 1982; Williams and North, 1984; Aghajanian and Wang, 1987) or when administered in vivo (Korf et al., 1974; Valentino and Wehby, 1988a). Despite this evidence, opiate antagonists have no effect on LC discharge evoked by electrical stimulation of opioidcontaining afferents (Aston-Jones et al., 1992) or on spontaneous LC activity, leaving open to question the role of opioids within the LC.

The LC is activated by physiological and environmental stressors, and this is thought to play a role in cognitive aspects of the stress response (Valentino et al., 1993). Previous studies provided indirect evidence for endogenous opioid release in the LC during restraint stress (Abercrombie and Jacobs, 1988) or sciatic nerve stimulation (Nissbrandt et al., 1982). One physiological stressor

This article is published in The Journal of Neuroscience, Rapid Communications Section, which publishes brief, peerreviewed papers online, not in print. Rapid Communications are posted online approximately one month earlier than they would appear if printed. They are listed in the Table of Contents of the next open issue of JNeurosci. Cite this article as: JNeurosci, 2001, 21:RC152 (1-5). The publication date is the date of posting online at www.jneurosci.org.

http://www.jneurosci.org/cgi/content/full/5370 
that increases LC discharge rate is hypotensive challenge (Svensson, 1987). We demonstrated previously that corticotropinreleasing factor (CRF) neurotransmission in the LC underlies LC and cortical electroencephalographic activation produced during hypotensive stress (Valentino et al., 1991; Page et al., 1993; Curtis et al., 1994). We also noted that termination of the stress and return to normotension is associated with inhibition of LC discharge rates below pre-stress values.

Because endogenous opioids innervate and inhibit LC neurons, this study tested the hypothesis that LC inhibition associated with termination of hypotensive stress is mediated by endogenous opioids. Additionally, the hypothesis that endogenous opioids are nonspecifically released in the LC by other stimuli that elicit a rise in blood pressure was examined.

\section{MATERIALS AND METHODS}

Animals. The subjects were adult male Sprague Dawley rats (Taconic Farms, Germantown, NY) weighing $\sim 300 \mathrm{gm}$ at the beginning of the experiments. Rats were initially housed three to a cage in a controlled environment $\left(20^{\circ} \mathrm{C}, 12 \mathrm{hr}\right.$ light/dark cycle, lights on at 7:00 A.M.). Food and water were available ad libitum. Care and use of animals was in accordance with the NIH Guide for the Care and Use of Laboratory Animals.

Surgery. The procedures used for recording LC discharge of halothaneanesthetized rats were similar to those described previously (Curtis et al., 1997). Rats were anesthetized with $2 \%$ halothane-in-air mixture administered through a nose cone. The jugular vein was cannulated for infusion of nitroprusside. The femoral artery was cannulated for blood pressure recordings. The anesthetic was maintained at $1 \%$ throughout the experiment. Body temperature was maintained at $36-37^{\circ} \mathrm{C}$ by a feedbackcontrolled heating pad. Rats were positioned in a stereotaxic instrument using blunt ear bars, with the head oriented at a $15^{\circ}$ angle to the horizontal plane (nose down). The skull was exposed, and a hole centered at $1.1 \mathrm{~mm}$ lateral to the midline and $3.7-3.9 \mathrm{~mm}$ caudal to the intersection of midline and lambda was drilled over the cerebellum for approaching the LC.

Recording. Double-barrel glass micropipettes were used to record single-unit LC discharge and simultaneously microinfuse either a CRF antagonist ([D-Phe $\left.{ }^{12}, \mathrm{Nle}^{21,38}, \mathrm{C}^{\alpha} \mathrm{MeLeu}^{37}\right] \mathrm{r} / \mathrm{hCRF}(12-41)$; D-PheCRF ${ }_{12-41}$ ) or naloxone (Akaoka et al., 1992; Curtis et al., 1997). The recording pipette (2-4 $\mu \mathrm{m}$ diameter tip; 4-7 M 2 ) was filled with Pontamine Sky Blue dye (PSB) in $0.5 \mathrm{M}$ sodium acetate buffer. The infusion pipette $(20-50 \mu \mathrm{m}$ diameter tip) was angled at $\sim 30-45^{\circ}$ with its tip adjacent to the tip of the recording pipette but $100-120 \mu \mathrm{m}$ dorsal. This was connected by polyethylene tubing to a source of solenoid-activated pneumatic pressure (Picospritzer; General Valve, Fairfield, NJ) and calibrated such that known volumes could be administered ( $1 \mathrm{~mm}$ displacement is equivalent to $60 \mathrm{nl}$ ). Intracerulear infusions were made by applying small pulses of pressure (5-25 psi, $10-30 \mathrm{msec}$ in duration) to the peptide-containing barrel at a frequency of $0.2-1 \mathrm{~Hz}$ to deliver a volume of $30 \mathrm{nl}$.

The pipette was advanced toward the $\mathrm{LC}$ with a micromanipulator. Microelectrode signals were amplified and filtered. Impulse activity was monitored with an oscilloscope and a loudspeaker to aid in localizing the LC. LC neurons were tentatively identified during the recording by their spontaneous discharge rates $(0.5-5 \mathrm{~Hz})$, entirely positive, notched waveforms ( 2 to 3 msec duration) and biphasic excitatory-inhibitory responses to contralateral hindpaw or tail pinch. When stable, unitary action potentials were isolated, and a window discriminator was used to convert the occurrence of each action potential into digital pulses, which were led into a Gateway (San Diego, CA) computer via a CED 1401 Plus interface (Cambridge Electronic Design, Cambridge, UK) using Spike 2 software for on-line visualization and storage and off-line analysis.

Protocol. Baseline LC discharge rate was recorded for at least $9 \mathrm{~min}$, and then nitroprusside was inf used through the intravenous cannula ( 0.33 $\mathrm{mg} / \mathrm{ml}, 30 \mu \mathrm{l} / \mathrm{min}, 15 \mathrm{~min}$ duration). LC discharge rate and mean arterial blood pressure were continuously recorded during the infusion. Mean arterial blood pressure was monitored with a pressure transducer and amplifier, and the signal was led to a computer via a CED 1401 Plus interface using Spike 2 software. For experiments involving intracerulear inf usion of D-PheCRF $\mathrm{F}_{12-41}$ or naloxone, LC discharge rate was recorded for at least $9 \mathrm{~min}$ before the microinfusion, and nitroprusside was administered 6 min later. Only one cell from an individual rat was tested.
Histology. The recording site was marked by iontophoresis $(-15 \mu \mathrm{A}$, $10 \mathrm{~min}$ ) of PSB at the end of the experiment. Rats were anesthetized with pentobarbital $(100 \mathrm{mg} / \mathrm{kg}$, i.p.) and perfused with a $10 \%$ solution of paraformaldehyde in phosphate buffer. Brains were removed, and frozen $40-\mu \mathrm{m}$-thick coronal sections were cut on a cryostat, mounted on gelatinized glass slides, and stained with neutral red for localization of the PSB spot. The data presented are from neurons that were histologically identified as being within the nucleus LC (Valentino et al., 1983).

Drugs. D-PheCRF ${ }_{12-41}$ was obtained from Dr. Jean Rivier of the Clayton Foundation Laboratory for Peptide Biology (The Salk Institute, San Diego, CA). The peptide was dissolved in water to make a $1.0 \mathrm{mg} / \mathrm{ml}$ solution. Aliquots $(10 \mu \mathrm{l})$ of this solution were concentrated using a Savant Speed Vac concentrator. The $10 \mu \mathrm{g}$ aliquots were stored at $-70^{\circ} \mathrm{C}$ and dissolved in $30 \mu \mathrm{l}$ of artificial CSF (ACSF) on the day of the experiment. Naloxone was obtained from Research Biochemicals (Natick, MA) and was dissolved in a concentration of $0.33 \mathrm{mg} / \mathrm{ml}$ in ACSF. Sodium nitroprusside (Sigma, St. Louis, MO) was dissolved in saline $(0.33 \mathrm{mg} / \mathrm{ml})$ and infused intravenously at a rate of $30 \mu \mathrm{l} / \mathrm{min}$ for $15 \mathrm{~min}$.

\section{RESULTS}

\section{The LC is activated by hypotensive stress and inhibited by termination of the stress}

The mean spontaneous discharge rates of $30 \mathrm{LC}$ neurons recorded from 30 rats was $1.7 \pm 0.2 \mathrm{~Hz}$, and baseline mean arterial pressure was $78 \pm 2 \mathrm{mmHg}(n=22$ rats). As reported previously (Svensson, 1987; Valentino and Wehby, 1988b), nitroprusside inf usion decreased mean arterial blood pressure by $53 \pm 3 \%(n=$ 8 rats) (Fig. 1a). This was accompanied by an increase in LC discharge rate over the course of the infusion (Figs. 1b, 2a), with a mean maximal increase of $41 \pm 7 \%(p<0.001$; Student's $t$ test for matched pairs) (Fig. 2b). When the inf usion was terminated, mean arterial blood pressure returned to baseline, and LC discharge significantly decreased below baseline values $6-9$ min after termination of the challenge $(p<0.02$; Student's $t$ test for matched pairs), as reported previously (Valentino and Wehby, 1988b) (Fig. 1, 2a). The mean maximal decrease in LC discharge occurring over the 9 min after the termination of the infusion was $19 \pm 6 \%(p<0.02$; Student's $t$ test for matched pairs).

\section{LC inhibition is enhanced in the presence of a CRF antagonist}

As reported previously (Curtis et al., 1994), microinf usion of the pure CRF antagonist D-PheCRF $\mathrm{C}_{12-41}$ adjacent to the recording electrode prevented LC activation during hypotensive challenge $\left(F_{(1,87)}=20.3 ; p=0.002\right.$; two-way ANOVA) (Figs. 1,2$)$. The previous study did not examine the effects of this pure CRF antagonist after the termination of the challenge. As shown in Figure $2 a$, in rats pretreated with $\mathrm{D}-\mathrm{PheCRF}_{12-41}$, the inhibition associated with the termination of the challenge occurred at an earlier time and was of a greater magnitude. Thus, LC discharge rate was significantly decreased by 3 min after termination of the challenge in D-PheCRF $\mathrm{F}_{12-41}$-pretreated rats $(p<0.005$; Student's $t$ test for matched pairs) (Fig. $2 a$ ), and the maximum magnitude of the inhibition was a $40 \pm 5 \%$ decrease in discharge rate from baseline ( $p<0.02$; Student's $t$ test for matched pairs) (Fig. $2 b$ ). The potentiation of post-stress inhibition in rats pretreated with D-PheCRF ${ }_{12-41}$ implied that the CRF antagonist unmasks the presence of an inhibitory influence.

\section{Termination of hypotensive stress engages endogenous opioid release in the LC}

Evidence for a role of endogenous opioids in the post-stress LC inhibition was demonstrated in rats in which naloxone (10 ng in 30 nl) was microinfused into the $\mathrm{LC}$ adjacent to the recording electrode. In contrast to the CRF antagonist, naloxone did not 
a.
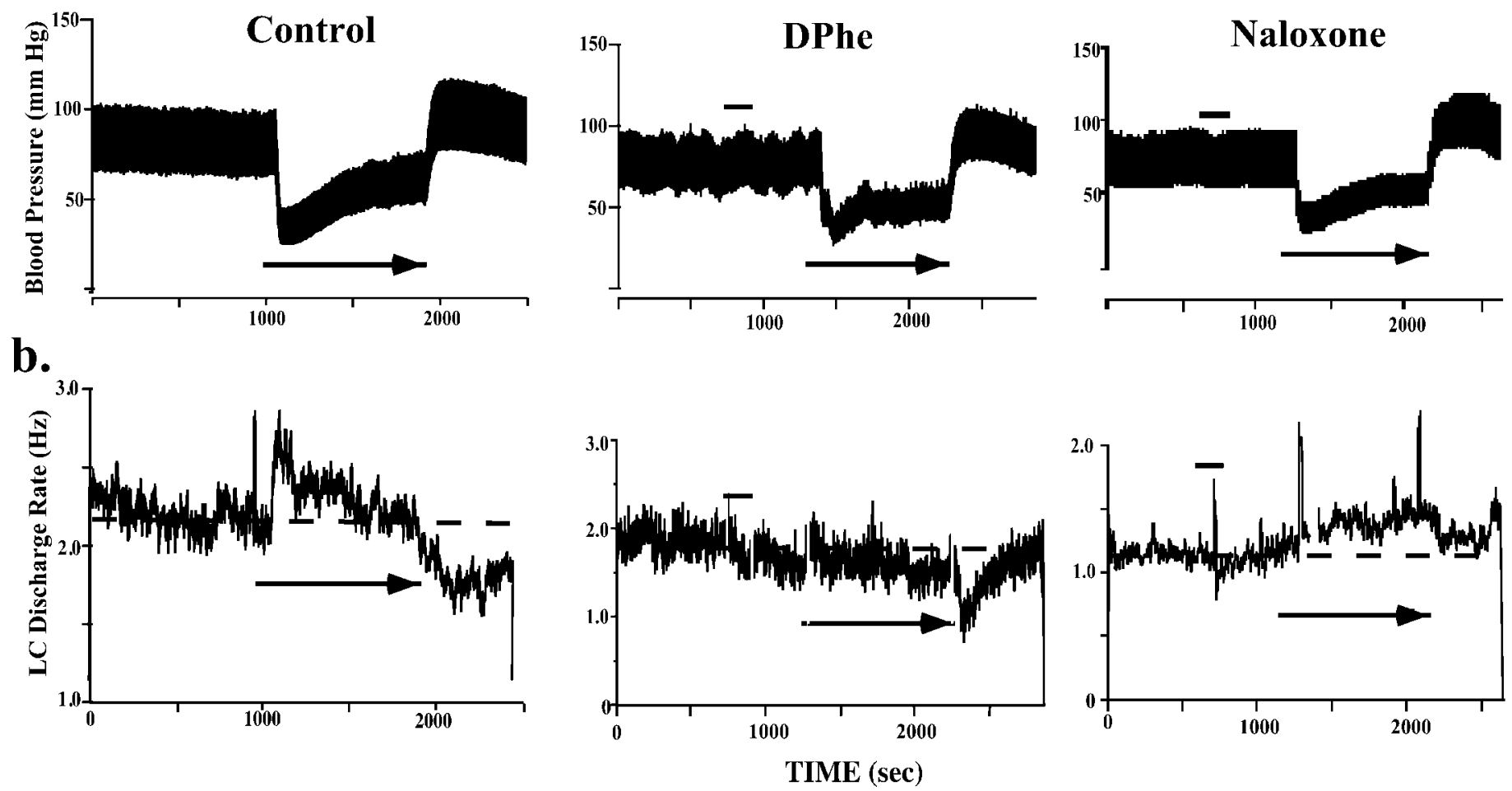

Figure 1. Examples of raw traces of blood pressure $(a)$ and LC unit activity $(b)$ before, during, and after hypotensive challenge in rats without pretreatment (Control), pretreated with D-PheCRF 12-41 $_{6} 6 \mathrm{~min}$ before nitroprusside infusion (DPhe), and pretreated with naloxone 6 min before nitroprusside inf usion (Naloxone). The arrows below the traces indicate the duration of nitroprusside inf usion. The bar above the traces indicates the time of administration of the antagonists. The abscissas in $a$ and $b$ indicate time in seconds. In $a$, the ordinates indicate mean arterial blood pressure in millimeters mercury. In $b$, the ordinates indicate LC discharge rate (in Hertz). The dotted horizontal lines in $b$ represent the mean LC discharge rate before nitroprusside infusion. Note that the blood pressure responses to nitroprusside inf usion are comparable in all rats, but responses of LC neurons differ depending on the pretreatment.

alter the magnitude or time course of LC activation during the hypotensive challenge $\left(F_{(1,83)}=0.001 ; p=0.9\right.$; two-way ANOVA) (Figs. $1 b, 2 a$ ). Additionally, the maximum magnitude of activation occurring during hypotensive challenge was not significantly different than that observed in naïve rats $(p=0.3$; Student's $t$ test for independent samples) (Fig. 2b). Importantly, inhibition of LC discharge rate that typically occurred with the termination of the stress was absent in rats pretreated with naloxone (Figs. 1b, 2a). LC discharge rate 6 and 9 min after the termination of the infusion was significantly greater in the naloxone-pretreated group versus controls ( $p \leq 0.01$; Student's $t$ test for independent samples). In the naloxone-treated group, the mean of the lowest discharge rate recorded up to 9 min after the termination of the challenge was equivalent to a $6 \pm 4 \%$ increase in discharge rate above baseline values versus a $19 \pm 6 \%$ decrease in the control group (Fig. $2 b$ ). Neither D-PheCRF ${ }_{12-41}$ nor naloxone produced significant effects on basal LC discharge $\left(F_{(2,53)}\right.$ $=2.2 ; p>0.1)$ or basal mean arterial pressure $\left(F_{(2,21)}=2.7 ; p=\right.$ 0.1) compared with ACSF (see examples in Fig. 1). Also, the magnitude of hypotension produced by nitroprusside infusion was not altered by D-PheCRF ${ }_{12-41}$ or naloxone $\left(F_{(2,21)}=0.1 ; p>\right.$ 0.1) compared with ACSF.

Termination of the hypotensive challenge was associated with a rise in blood pressure that was correlated to inhibition of LC discharge rate. To determine whether endogenous opioids are released in the $\mathrm{LC}$ under other circumstances that result in a rise in mean arterial pressure, LC discharge and blood pressure were recorded simultaneously during administration of arginine vasopressin. In rats pretreated with ACSF (30 nl) microinfused into the LC, arginine vasopressin (100 ng/ $\mathrm{kg}$, i.v.) increased blood pressure by $29 \pm 5 \%$, and this was associated with a $22 \pm 5 \%(n=$ 4) decrease in LC discharge rate. Pretreatment with naloxone (10 $\mathrm{ng}$ in $30 \mathrm{nl}$ of ACSF) microinfused into the LC had no effect on either the magnitude of blood pressure elevation ( $34 \pm 8 \%$ ) or LC inhibition $(16 \pm 2 \%)$ produced by vasopressin $(n=4 ; p=0.35$; Student's $t$ test for independent samples).

\section{DISCUSSION}

The present findings demonstrated that LC inhibition associated with the termination of hypotensive stress is abolished by local microinfusion of an opiate antagonist into the LC. Local microinfusion of naloxone did not alter the magnitude of hypotension or LC activation produced during the hypotensive challenge. These findings provide evidence for functional release of endogenous opioids within the LC, a nucleus known to be densely targeted by opioid peptides. In contrast to previous studies that required high-frequency electrical stimulation to reveal antagonist-sensitive opioid effects in brain circuits (Caudle et al., 1991; Xie and Lewis, 1991; Wagner and Chavkin, 1995), the present effect was apparent during a physiological stimulus. The finding that naloxone did not alter LC inhibition associated with a vasopressin-induced rise in blood pressure argues against a nonselective release of endogenous opioids in the LC during a rise in blood pressure. Rather, the opioid effect is specifically 
a.

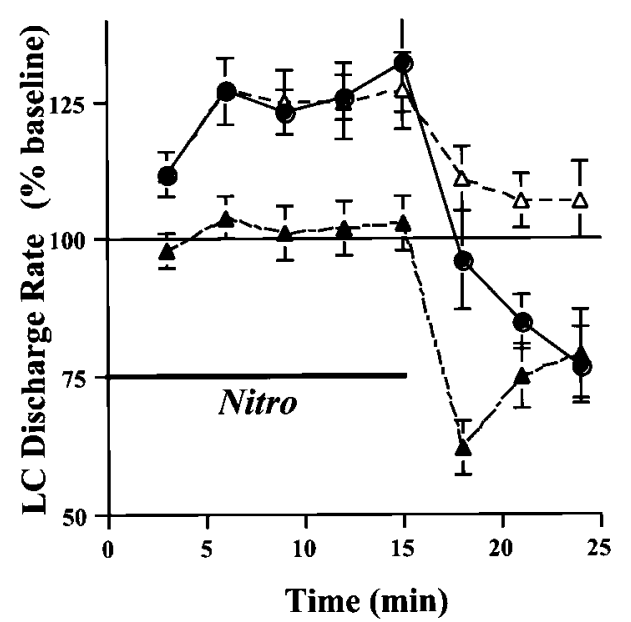

b.

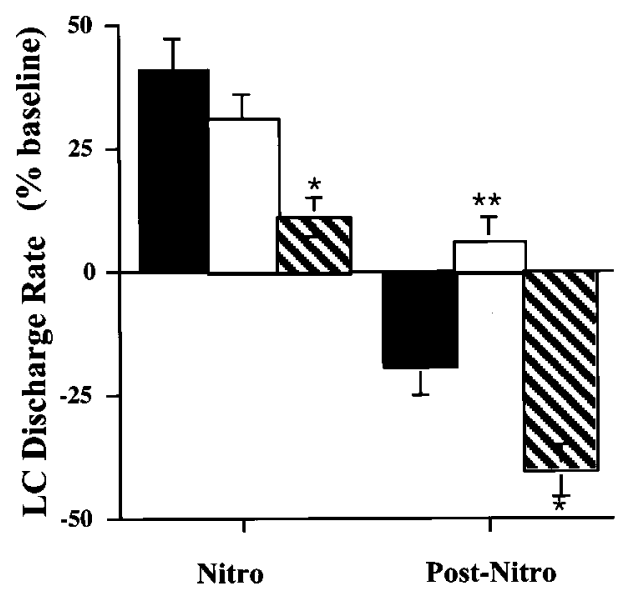

Figure 2. Mean effect of hypotensive challenge on LC discharge in rats pretreated with naloxone or D-PheCRF ${ }_{12-41} . a$, The ordinate indicates LC discharge rate expressed as a percentage of the mean baseline rate determined over 9 min before nitroprusside infusion. The mean baseline discharge rates were $1.7 \pm 0.2,1.8 \pm 0.3$, and $1.5 \pm 0.3 \mathrm{~Hz}$ for rats that were not administered antagonists ( filled circles; $n=13$ ), rats that were pretreated with naloxone (open triangles; $n=8$ ), and rats that were pretreated with D-PheCRF $\mathrm{C}_{12-41}$ ( filled triangles; $n=9$ ), respectively. These baseline rates were not significantly different between groups $\left(F_{(2,27)}=0.27\right)$. The time of the infusion is indicated by the line above Nitro. Vertical lines represent \pm 1 SEM. $b$, Bars above Nitro represent the mean maximum increase in LC discharge occurring at anytime over the 15 min infusion. Bars above Post-Nitro represent the mean lowest discharge rate (expressed as a percentage of pre-nitroprusside baseline) occurring at anytime up to 9 min after the termination of the infusion. Naïve, naloxone-pretreated, and D-PheCRF ${ }_{12-41}$-pretreated rats are represented by filled, open, and hatched bars, respectively. The asterisk above the hatched bar at Nitro indicates a statistically significant difference between D-PheCRF ${ }_{12-41}$-pretreated and naive groups $(p<0.005)$. The asterisks above the open bar at Post-Nitro indicate a statistically significant difference compared with the naïve group $(p<0.005)$. The asterisk by the hatched bar indicates a statistically significant difference compared with the naïve group $(p<0.02)$. Vertical lines represent \pm 1 SEM.

apparent during the termination of hypotensive stress. Engaging opioid release at this time may serve to counterbalance excitatory effects of CRF on the LC-norepinephrine system, thereby limiting its activation by stress.

Interpretations of the present results rely on the specificity of naloxone as an opioid antagonist. Although naloxone has been reported to have GABA antagonist activity at relatively high doses (Dingledine et al., 1978), this action would be expected to activate LC neurons (Shiekhattar and Aston-Jones, 1992). The apparent lack of activation by the dose of naloxone used in the present study argues against GABA antagonism as a mechanism of action of naloxone. Importantly, the dose of naloxone used in this study is comparable with the intracerulear dose used in previous studies (Guyenet and Aghajanian, 1979; Aston-Jones et al., 1997) and determined to be specific (Guyenet and Aghajanian, 1979).

The present results are consistent with a previous observation that systemically administered naloxone increases LC activity of rats exposed to stress but not unstressed rats (Abercrombie and Jacobs, 1988). Because naloxone was administered systemically in that previous study, a site of action within or outside of the LC could not be discerned. In contrast, the efficacy of intracerulear administration of naloxone in relatively low volumes in the present study points to a site of action of endogenous opioids within the LC and supports the idea that these peptides act as direct neuromodulators of this system. Together, these studies provide evidence for selective release of opioids in the LC by stress-related stimuli.

CRF and enkephalin-immunoreactive axon terminals overlap in the rostrolateral peri-LC in which LC dendrites extend and both types of terminals form synaptic specializations with LC dendrites in this region (Van Bockstaele et al., 1995, 1998). Electron microscopic analysis of sections double-labeled for CRF and enkephalin revealed colocalization of the peptides in axon terminals in the rostrolateral LC dendritic zone, although terminals that were labeled for only one peptide were more predominant (Valentino and Van Bockstaele, 2001). It is possible that hypotensive stress elicits corelease of CRF and enkephalin from the same terminals or separate terminals that converge on the same LC dendrites. Consistent with this, hypotensive stress decreased LC discharge in rats pretreated with $\alpha$ helical $\mathrm{CRF}_{9-41}$ (Valentino et al., 1991), a CRF antagonist that has been suggested have partial agonist activity (Rainnie et al., 1992). Although this was observed in some individual rats in the present study, this was not a consistent finding. Rather, the present results suggest that a stimulus associated with the termination of the stress initiates opioid release in the LC region. This stimulus is not solely a rise in blood pressure, because LC inhibition associated with hypertension produced by vasopressin was unaffected by naloxone.

The stress response is composed of coordinated reactions of multiple systems to a challenge to homeostasis. Because these reactions can have deleterious effects in the absence of the stressor, an adaptive component of the stress response is that it terminates with termination of the stressor. For example, activation of the hypothalamic-pituitary-adrenal axis, the endocrine limb of the stress response, is limited through fast feedback regulation exerted by corticosteroids. These act at a suprapituitary level to inhibit CRF release into the median eminence (Keller-Wood and Dallman, 1984; Munck et al., 1984). Activation of the LC-noradrenergic system may be part of a cognitive limb of the stress response, serving to increase arousal and alter attention such that adaptive behaviors are facilitated (Valentino and Aston-Jones, 1995). As for the endocrine limb of the stress response, counter-regulatory mechanisms must be in place to limit this cognitive limb. In the absence of such mechanisms, inappropriate or prolonged LC activation could result in hyperarousal and attentional dysfunction and disruption of behaviors requiring focused attention. The present results suggest that 
opioid afferents to the LC are engaged during or by the termination of stress, resulting in inhibition of LC activity. This inhibition may serve to balance or limit activation of this system by CRF or other stress neuromediators.

\section{REFERENCES}

Abercrombie ED, Jacobs BL (1988) Systemic naloxone administration potentiates locus coeruleus noradrenergic neuronal activity under stressful but not non-stressful conditions. Brain Res 441:362-366.

Aghajanian GK, Wang Y-Y (1987) Common alpha 2 and opiate effector mechanisms in the locus coeruleus: intracellular studies in brain slices. Neuropharmacology 26:793-799.

Akaoka H, Saunier C-F, Chergui K, Charlety P, Buda M, Chouvet G (1992) Combining in vivo volume-controlled pressure microejection with extracellular unit recording. J Neurosci Methods 42:119-128.

Aston-Jones G, Astier B, Ennis M (1992) Inhibition of locus coeruleus noradrenergic neurons by $\mathrm{C} 1$ adrenergic cells in the rostral ventral medulla. Neuroscience 48:371-382.

Aston-Jones G, Hirata H, Akaoka H (1997) Local opiate withdrawal in locus coeruleus in vivo. Brain Res 765:331-336.

Caudle RM, Wagner JJ, Chavkin CI (1991) Endogenous opioids released from perforant path modulate norepinephrine actions and inhibitory postsynaptic potentials in guinea pig CA3 pyramidal cells. J Pharmacol Exp Ther 258:18-26.

Curtis AL, Grigoradis D, Page ME, Rivier J, Valentino RJ (1994) Pharmacological comparison of two corticotropin-releasing factor antagonists: in vivo and in vitro studies. J Pharmacol Exp Ther 268:359-365

Curtis AL, Florin-Lechner SM, Pavcovich LA, Valentino RJ (1997) Activation of the locus coeruleus noradrenergic system by intracoerulear microinfusion of corticotropin-releasing factor: effects on discharge rate, cortical norepinephrine levels and cortical electroencephalographic activity. J Pharmacol Exp Ther 281:163-172.

Derrick BE, Rodriguez SB, Lieberman DN, Martinez JL (1992) Mu opioid receptors are associated with the induction of hippocampal mossy fiber long-term potentiation. J Pharmacol Exp Ther 263:725-733.

Dingledine R, Iversen LL, Breuker E (1978) Naloxone as a GABA antagonist: evidence from iontophoretic, receptor binding and convulsant studies. Eur J Pharmacol 47:19-27.

Drolet G, Van Bockstaele EJ, Aston-Jones G (1992) Robust enkephalin innervation of the locus coeruleus from the rostral medulla. J Neurosci 12:3162-3174

Fallon JH, Leslie FM (1986) Distribution of dynorphin and enkephalin peptides in the rat brain. J Comp Neurol 249:293-336.

Finley JCW, Maderdrut JL, Petrusz P (1981) The immunocytochemical localization of enkephalin in the central nervous system of the rat. J Comp Neurol 198:541-565.

Guyenet PG, Aghajanian GK (1979) ACh, substance-p and metenkephalin in the locus coeruleus: pharmacological evidence for independent sites of action. Eur J Pharmacol 53:319-328.

Haber S, Elde R (1982) The distribution of enkephalin immunoreactive fibers and terminals in the monkey central nervous system: an immunohistochemical study. Neuroscience 7:1049-1095.

Keller-Wood ME, Dallman MF (1984) Corticosteroid inhibition of ACTH secretion. Endocr Rev 5:1-24.

Khachaturian H, Lewis ME, Watson SJ (1983) Enkephalin systems in the diencephalon and brainstem of the rat. J Comp Neurol 220:310-320.

Khachaturian H, Lewis ME, Schafer MK-H, Watson SJ (1985) Anatomy of the CNS opioid systems. Trends Neurosci 8:111-119.

Korf J, Bunney BS, Aghajanian GK (1974) Noradrenergic neurons: morphine inhibition of spontaneous activity. Eur J Pharmacol 25:165-169.
Mansour A, Khachaturian H, Lewis ME, Akil H, Watson SJ (1988) Anatomy of CNS opioid receptors. Trends Neurosci 11:308-314.

Munck A, Guyre PM, Holbrook NJ (1984) Physiological functions of glucocorticoids in stress and their relation to pharmacological actions. Endocr Rev 5:25-55.

Nissbrandt H, Yao T, Thoren P, Svensson TH (1982) Naloxone reversible reduction in brain monoamine synthesis after sciatic nerve stimulation. J Neural Transm 53:91-100.

Page ME, Berridge CW, Foote SL, Valentino RJ (1993) Corticotropinreleasing factor in the locus coeruleus mediates EEG activation associated with hypotensive stress. Neurosci Lett 164:81-84.

Rainnie DG, Fernhout BJH, Shinnick-Gallagher P (1992) Differential actions of corticotropin releasing factor on basolateral and centralamygdaloid neurons, in vitro. J Pharmacol Exp Ther 263:846-858.

Shiekhattar R, Aston-Jones G (1992) Local application of bicuculline potentiates NMDA-receptor-mediated sensory responses of brain noradrenergic neurons. Synapse 10:54-61.

Svensson TH (1987) Peripheral, autonomic regulation of locus coeruleus noradrenergic neurons in brain: putative implications for psychiatry and psychopharmacology. Psychopharmacology 92:1-7.

Uhl GR, Goodman RR, Kuhar MJ, Childers SR, Snyder SH (1979) Immunohistochemical mapping of enkephalin containing cell bodies, fibers, and nerve terminals in the brainstem of the rat. Brain Res 166:75-94.

Valentino RJ, Aston-Jones G (1995) Physiological and anatomical determinants of locus coeruleus discharge. Behavioral and clinical implications. In: Psychopharmacology: the fourth generation of progress (Bloom FE, Kupfer DJ, eds), pp 373-386. New York: Raven.

Valentino RJ, Van Bockstaele EJ (2001) Opposing regulation of the locus coeruleus by corticotropin-releasing factor and opioids: potential for reciprocal interactions between stress and opioid sensitivity. Psychopharmacology, in press.

Valentino RJ, Wehby RG (1988a) Morphine effects on locus coeruleus neurons are dependent on the state of arousal and availability of external stimuli: studies in anesthetized and unanesthetized rats. J Pharmacol Exp Ther 244:1178-1186.

Valentino RJ, Wehby RG (1988b) Corticotropin-releasing factor: Evidence for a neurotransmitter role in the locus coeruleus during hemodynamic stress. Neuroendocrinology 48:674-677.

Valentino RJ, Foote SL, Aston-Jones G (1983) Corticotropin-releasing factor activates noradrenergic neurons of the locus coeruleus. Brain Res 270:363-367.

Valentino RJ, Page ME, Curtis AL (1991) Activation of noradrenergic locus coeruleus neurons by hemodynamic stress is due to local release of corticotropin-releasing factor. Brain Res 555:25-34.

Valentino RJ, Foote SL, Page ME (1993) The locus coeruleus as a site for integrating corticotropin-releasing factor and noradrenergic mediation of stress responses. Ann NY Acad Sci 697:173-188.

Van Bockstaele EJ, Branchereau P, Pickel VM (1995) Morphologically heterogeneous met-enkephalin terminals form synapses with tyrosine hydroxylase containing dendrites in the rat nucleus locus coeruleus: an immuno-electron microscopic analysis. J Comp Neurol 363:423-438.

Van Bockstaele EJ, Colaga EEO, Valentino RJ (1998) Amygdaloid corticotropin-releasing factor targets locus coeruleus dendrites: substrate for the coordination of emotional and cognitive limbs of the stress response. J Neuroendocrinol 10:743-757.

Wagner JJ, Chavkin CI (1995) Neuropharmacology of endogenous opioid peptides. In: Psychopharmacology: The fourth generation of progress (Bloom FE, Kupfer DJ, ed), pp 519-530. New York: Raven.

Williams JT, North RA (1984) Opiate receptor interactions on single locus coeruleus neurons. Mol Pharmacol 26:489-497.

Williams JT, Egan TM, North RA (1982) Enkephalin opens potassium channels on mammalian central neurons. Nature 299:74-77.

Xie C-W, Lewis DV (1991) Opioid-mediated facilitation of long-term potentiation at the lateral perforant path-dentate granule cell synapse. J Pharmacol Exp Ther 256:289-296. 